\title{
When should communities and conservationists monitor exploited resources?
}

\author{
NEAL J. HOCKLEY ${ }^{1,2}$,*, JULIA P.G. JONES ${ }^{2,3}$, FORTUNAT \\ B. ANDRIAHAJAINA ${ }^{2}$, ANDREA MANICA ${ }^{3}$, EMMA \\ H. RANAMBITSOA ${ }^{2}$ and JEAN A. RANDRIAMBOAHARY ${ }^{2}$ \\ ${ }^{1}$ School of Agricultural and Forest Sciences, University of Wales, Bangor, Gwynedd. LL57 2UW, \\ UK; ${ }^{2}$ Vokatry ny Ala, BP1067, Fianarantsoa 301, Madagascar; ${ }^{3}$ Department of Zoology, University \\ of Cambridge, Downing Street, Cambridge CB2 3EJ, UK; *Author for correspondence (e-mail: \\ afpe5d@bangor.ac.uk; fax: +44-(0)-1248-354997)
}

Received 5 April 2004; accepted in revised form 15 September 2004

Key words: Common property resources, Community-based conservation, Crayfish, Efficiency, Locally-based monitoring, Madagascar, Mark-and-recapture, Non-timber forest products, Participatory monitoring, Power analysis, Sustainable harvesting, Willingness to pay

\begin{abstract}
Both conservationists and harvesters may be willing to contribute to participatory monitoring of exploited species. However, this can be costly and stakeholders need to choose whether monitoring programs or other alternatives, such as a moratorium or unmonitored exploitation, meet their objectives most efficiently. We discuss when, and how much, stakeholders may be willing to contribute to monitoring of exploited resources. We predict that communities' contributions will usually be much less than the annual value of the harvest, and will be affected by their dependency upon it; their discount rate; its cultural importance, vulnerability to overexploitation and amenability to monitoring. 'Efficient' conservationists' willingness to contribute should be similar to that of communities', since monitoring and management programs must compete with compensated moratoria. The combined willingness to contribute of both stakeholder groups will usually be much less than twice the annual revenue from the resource. Applying this framework to a case-study of crayfish harvesting in Madagascar, we find that the total willingness to contribute to monitoring is likely to be insufficient to support conventional monitoring efforts. We conclude that conservation planners must be realistic about what stakeholders are willing to contribute to monitoring programmes and consider low cost methods or negotiated moratoria.
\end{abstract}

\section{Introduction}

Throughout the developing world, rural people meet many of their needs by harvesting wildlife (e.g. Pimentel et al. 1997). However, there is concern that many exploited species are threatened by overharvesting (Mace and Reynolds 2001). A number of authors have stressed the importance of monitoring harvested species in order to avoid unsustainable exploitation (e.g. Kremen et al. 1998; Wong et al. 2001). However, monitoring can divert scarce resources away from conservation or other priorities while being of little management value (Sheil 2001). Danielsen et al. (2000) suggest that the resources available for conservation in developing countries cannot stretch to programs that 
produce internationally comparable results but that low-cost participatory monitoring programs can provide useful information for management. In many developing countries, the management of natural resources is being transferred to local people, conditional upon them carrying out monitoring and management activities (Wong et al. 2001; Topp-Jørgensen et al. 2005 (this issue)).

Communities and conservationists may invest in monitoring which allows sustainable exploitation to take place, if that is the most efficient way to achieve their respective goals. We develop a framework for determining when stakeholders may be expected to adopt monitoring programs, and how much they may be expected to contribute. We then apply this framework to the case of freshwater crayfish harvesting in Madagascar, and compare the value of harvests with the cost and effort required to monitor crayfish populations.

\section{Conceptual framework: stakeholder willingness to contribute}

Many authors have investigated the factors favouring the successful establishment of community institutions to manage common property resources and prevent a 'tragedy of the commons' (Poteete and Ostrom 2004). However, it is often assumed that the non-management and consequent degradation of the commons would indeed be a 'tragedy' for resource users. Yet overharvesting may be optimal (e.g. Policansky 1993) and the inherent variation in ecosystems may make it very hard to detect unsustainability (e.g. Leach et al. 1999). In these cases ignorance would be favoured, since the effort required to monitor and manage for sustainability may be greater than the benefits. This paper therefore focuses on the ecological and economic conditions, which will determine whether communities wish to manage and monitor their resources. This question is complementary to the question of whether communities are able to establish institutions to do this. We also analyse the likely actions of 'efficient' conservationists and the limits to their participation. We assume both harvesters and conservationists act rationally, and that they have perfect information about the costs, benefits and risks of their actions. While this will rarely be completely true (see Burke 2001), we feel it is legitimate to ask when stakeholders should monitor, not just when they will monitor. The criteria we propose are therefore minimum criteria, and throughout the paper we adopt assumptions which will tend to favour monitoring. Risk preferences and heterogeneity within communities are important considerations, but are beyond the scope of this paper (see Leach et al. 1999; Poteete and Ostrom 2004).

To consider the desirability and efficiency of proposed monitoring programs, compared with other alternatives (e.g. moratoriums or unmonitored exploitation), we analyse the objectives which stakeholders may have, and the means available to achieve them. We discuss the ecological and economic conditions, which are likely to favour monitoring and propose a method for estimating the contribution each stakeholder group can be expected to make. The aim is to 
help decision makers determine which, if any, monitoring programs may be likely to succeed in a specific situation and to identify areas which require further research.

We refer to Willingness to Contribute (WTC), rather than Willingness to Pay, to emphasise that this includes contributions of labour as well as cash. We refer to Monitoring and Management (hereafter M\&M), because we consider the case of monitoring programs explicitly intended to aid the management of exploited species. We seek to address the situation, common in developing countries, where sustainable exploitation is being proposed as a method of conservation, but which requires monitoring which would not have taken place otherwise. Although there are many cases where indigenous communities have developed natural resource management systems without outside assistance (see references in Feeny et al. 1990), we consider situations where this has not yet occurred and where conservationists and communities are concerned about the resource.

\section{Communities' willingness to contribute to monitoring}

If local people derive benefits (whether cultural, nutritional or financial) from harvesting a natural resource, then they may be willing to contribute to an M\&M program for that resource. How much, will depend on the degree to which $M \& M$ can increase the benefits they gain from the resource. M\&M will involve the direct costs of monitoring as well as opportunity costs of reducing harvests in some years. Benefits to the communities will be over the longer term, in the form of a reduced probability of population collapse through overexploitation. M\&M is therefore an investment, with future harvests providing the return. Assuming $M \& M$ aims to ensure harvests are sustainable, the annual costs of $M \& M$ which communities are prepared to contribute will be a proportion of the annual value of the maximum sustainable off take. It will not be greater than $100 \%$, but its exact percentage will depend on a number of factors, discussed below:

Dependency: The annual value of the resource to harvesters (or opportunity cost of not harvesting) will generally be less than the annual net revenue of the harvest, if alternative income or food sources are available.

Discount rate: High discount rates will reduce WTC to monitoring. Discount rates are higher for open access resources (e.g. Alvard 1998) and where security of tenure is low (as when there is a threat of a ban on harvesting).

Cultural value: Where the products or activity of harvesting (but not simply standing stock) have significant cultural value this will tend to favour M\&M which allows continued harvesting.

Vulnerability of resources to overharvesting: Resources which are very robust to harvesting will benefit little from M\&M. Very vulnerable resources will require conservative harvest levels, and/or intensive monitoring, which will disfavour M\&M. 
Amenability to monitoring: M\&M's effectiveness will depend on its ability to accurately record changes in the population. Resources which are easily counted and have low spatial and temporal variation will be easier to monitor for a given cost.

Benefits from monitoring: Monitoring must either increase the yields which can be harvested, for a given probability of resource collapse (by allowing more 'intelligent' harvesting) or reduce the probability of collapse, allowing harvests to continue into perpetuity. We used stochastic calculations of the Net Present Value (NPV) of harvests, with and without M\&M, to determine the maximum costs which communities would be willing to bear for monitoring programs of different effectiveness. We assumed favourable conditions for monitoring: $8 \%$ discount rate; $40 \mathrm{yr}$ time horizon; post-collapse harvest worth $5 \%$ of pre-collapse value; an average reduction in harvest due to $\mathrm{M} \& \mathrm{M}$ of $5 \%$, and $100 \%$ dependency on the resource. We found that if a harvested resource has an annual probability of collapse of $5 \%, M \& M$ would need to reduce this to roughly $1 \%$, to justify communities spending $20 \%$ of the net annual revenue of the sustainable harvest. There appears to be little quantitative information on the kinds of reductions in collapse probability which are achievable through $\mathrm{M} \& \mathrm{M}$, yet this is one of the key factors determining its value.

\section{Conservationist's willingness to contribute to monitoring}

We argue that conservationists' Willingness to Contribute (WTC) may generally be similar to that of local people's, and that it too will be related to, and less than, the annual net sustainable revenue from the harvest. This is because conservationists can choose between several management options. We consider three such options: (i) negotiate Compensated Moratorium (CM); (ii) monitor the exploited population to allow sustainable exploitation (M\&M); (iii) allow exploitation to continue unmonitored (Laissez Faire: LF). Table 1 below shows the options available to decision makers, and their associated costs.

Table 1. The economic and ecological costs associated with the management options considered.

\begin{tabular}{|c|c|c|c|}
\hline & Compensated Moratorium (CM) & $\begin{array}{l}\text { Monitoring and } \\
\text { Management (M\&M) }\end{array}$ & Laissez Faire $(\mathrm{LF})$ \\
\hline Economic & Opportunity & Opportunity costs & \\
\hline \multirow[t]{4}{*}{ Costs } & cost of Moratorium $\left(\mathrm{OC}_{\mathrm{CM}}\right)$ & of $\mathrm{M} \& \mathrm{M}\left(\mathrm{OC}_{\mathrm{M} \& \mathrm{M}}\right)$ & \\
\hline & & Costs of M\&M & \\
\hline & & Program $\left(C_{\mathrm{M} \& \mathrm{M}}\right)$ & \\
\hline & Enforcement Costs $\left(\mathrm{EC}_{\mathrm{CM}}\right)$ & $\begin{array}{l}\text { Enforcement Costs } \\
\left(\mathrm{EC}_{\mathrm{M} \& \mathrm{M}}\right)\end{array}$ & \\
\hline \multirow{2}{*}{$\begin{array}{l}\text { Ecological } \\
\text { Costs }\end{array}$} & None & Reduced Pristinity & Reduced Pristinity \\
\hline & $\begin{array}{l}\text { No risk of over- } \\
\text { harvesting }\end{array}$ & $\begin{array}{l}\text { Reduced risk of } \\
\text { over-harvesting }\end{array}$ & $\begin{array}{l}\text { Original risk of } \\
\text { over-harvesting }\end{array}$ \\
\hline
\end{tabular}


Conservationists may support the $\mathrm{M} \& \mathrm{M}$ option if it provides increased ecological integrity compared to the laissez faire approach. They may favour it over a Compensated Moratorium, if it avoids or reduces the need to compensate for the costs of lost opportunities to harvest.

Assuming that the laissez faire approach is unacceptable, conservationists will be prepared to support $\mathrm{M} \& \mathrm{M}$ where the combined costs of $\mathrm{M} \& \mathrm{M}\left(C_{\mathrm{M} \& \mathrm{M}}\right.$ : the enforcement costs $\left[\mathrm{EC}_{\mathrm{M \& M}}\right]$ plus the opportunity costs $\left[\mathrm{OC}_{\mathrm{M \& M}}\right]$ ) are less than the opportunity and enforcement costs of a Compensated Moratorium. Therefore, maximum WTC of conservationists for M\&M will be roughly equal to the opportunity costs of suspending the harvest, less the opportunity costs of managing it. This means conservationists' WTC will similar to and determined by, all of the same factors as communities'. This assumes that the resultant M\&M program results in similar ecological integrity to that provided by a moratorium and that conservationists act rationally to achieve the aims of their donors. This applies equally to species of great conservation value (e.g. rhinos). Although conservationists have a great WTC for rhino conservation, this should not equal their WTC for M\&M of rhino harvesting, unless the costs associated with a moratoria (the opportunity costs or value of the harvest) are prohibitively high.

\section{Conclusions from the conceptual framework}

Local people will favour M\&M where they break even or profit from it, and there is no net opportunity cost. Their contributions will usually be a small percentage of the annual net revenue of the sustainable harvest. Where local people's contributions are insufficient to cover the costs of M\&M, conservationists may also be prepared to contribute. This contribution will be less than the opportunity costs of a moratorium and therefore usually less than the annual net sustainable revenue. Thus, the total annual willingness to contribute to an M\&M program will rarely be greater than twice the annual net revenue of the sustainable harvest, and will usually be substantially less. Stakeholders could use current revenues as estimates of the sustainable revenue, and these can be estimated using participatory techniques.

\section{Case study: crayfish harvesting in Madagascar}

Ranomafana National Park in the eastern rainforests of Madagascar (Figure 1) contains 41,600 ha of humid evergreen forest, ranging in altitude from 500 to $1500 \mathrm{~m}$. (Wright and Andriamihaja 2004). Approximately 32,000 people (Korhonen et al. in press) live in the park's buffer zone. The economy of the area is based primarily on small-scale agriculture but forest product harvesting (of crayfish, eels, honey and fibres for weaving) is very important to many households (Ferraro 2002). 


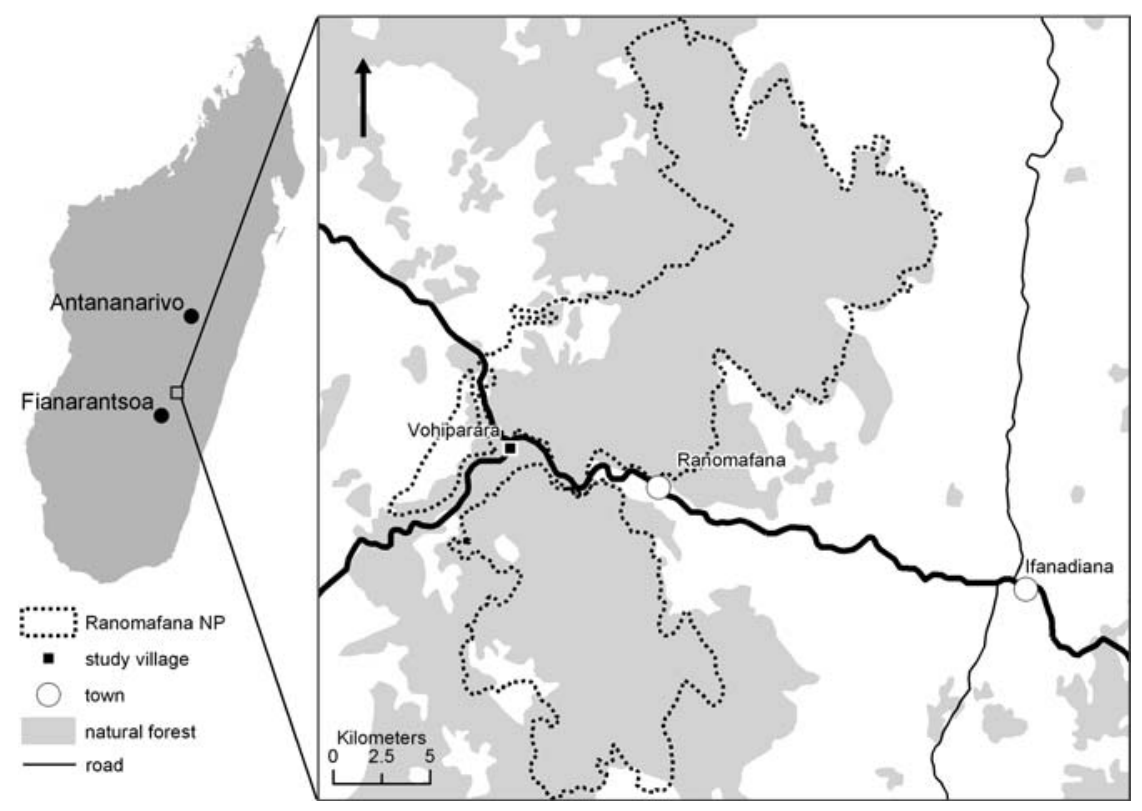

Figure 1. Location of the study area at Ranomafana National Park, Madagascar.

Since early 2001, we have been carrying out research into the sustainability and socio-economic importance of forest resource use around the park. In this paper, we focus on crayfish, one of the most important forest products in the area. We present data for Vohiparara (Figure 1), a village of 47 households where crayfish harvesting is extremely important economically (Jones 2004). We look at the value of crayfish to the community and compare this with the effort required to detect various declines in population using two different monitoring methods.

\section{Field methods}

Between March 2003 and January 2004 we carried out daily interviews with 22 crayfish harvesting households in Vohiparara. Each family participated in 5-16 interviews per month, in blocks of 5-8 days. In each interview, participants gave an account of all natural resource related, wage earning, agricultural or other significant activities they had carried out that day. Any forest products they collected were weighed or measured, and the sale value recorded. We present values converted to US $\$$ (using US $\$ 1=5712.4$ Malagasy Francs). The average daily returns from crayfish harvesting were estimated for each harvester (mean $=$ US $\$ 0.76$ per day), and multiplied by the estimated annual number of days spent crayfish harvesting to give an estimate of the gross returns from harvesting per harvester. We extrapolated from these estimates to cover the three harvesting households, which did not take part in the interviews. 
We compared two methods of assessing populations of crayfish. The first was a population estimate based on 5 days of mark-and-recapture; the second was a simple 1 day index of abundance based on the number of crayfish caught on the first day of mark-and-recapture.

Five consecutive days of mark-and-recapture were carried out at 79 sites across a range of harvesting intensities. This was part of a larger study on crayfish population dynamics (Jones 2004). Data collection relied heavily on community members both to catch the crayfish and as data recorders. Two harvesters and a recorder walked up a $100 \mathrm{~m}$ stretch of stream at a steady speed. Each crayfish caught was measured, given an individual identification and released. For analysis crayfish were split into three size classes but for simplicity we limit the following discussion to 'medium' crayfish $(35-50 \mathrm{~mm}$ carapace length); this class made up more than $75 \%$ of those harvested (Jones 2004). Closed population models run in the computer programme MARK (White and Burnham 1999) were used to estimate density at each site.

Using Monte Carlo simulations, we investigated the power of the 5 day density estimates to detect linear declines of $10-40 \%$ of the population over 5 years (equivalent to $1.9-7.0 \%$ annually) with varying numbers of visits per year (from 1 to 12). We varied the number of sites monitored from 1 to 20 , assuming that there was no variation between sites, i.e. sites were perfectly homogeneous. There was a significant relationship between the 1 day abundance index and the mark-and-recapture estimate $\left(F_{1,78}=29.05, p<0.001\right.$, $R^{2}=0.27$ ), we used this relationship to investigate how successful the 1 day indices of abundance would be at detecting similar declines.

\section{Results}

The mean annual crayfish earnings for the 22 households participating in interviews was US\$85, (range US\$21-180). Extrapolating to all 25 harvesting households gives a gross revenue from crayfish harvesting of US\$2041 per annum for the village of Vohiparara. If the current crayfish harvest is sustainable, the present value (using an $8 \%$ discount rate, and 40 year time horizon) of crayfish harvesting revenue to Vohiparara harvesters is US\$26,379.

The power of the 5 day estimates to detect declines of varying magnitude is shown in Figure 2. The power would be adequate ( $>80 \%$ ) to detect a $40 \%$ decline if a single site was monitored five times, or multiple sites monitored just once a year ( $>75$ person days of data collection). However, a $40 \%$ decline in an already harvested population would be extremely serious. The power to detect more useful declines is much weaker; for example a $20 \%$ decline could not be detected by sampling at a single site but could be picked up with an $80 \%$ power with two annual visits to 10 sites, or one visit to 20 sites (i.e. 300 person days).

The 1 day indices are much less powerful; using them it is not possible to detect any of the declines tested with meaningful power if sampling at just one, 

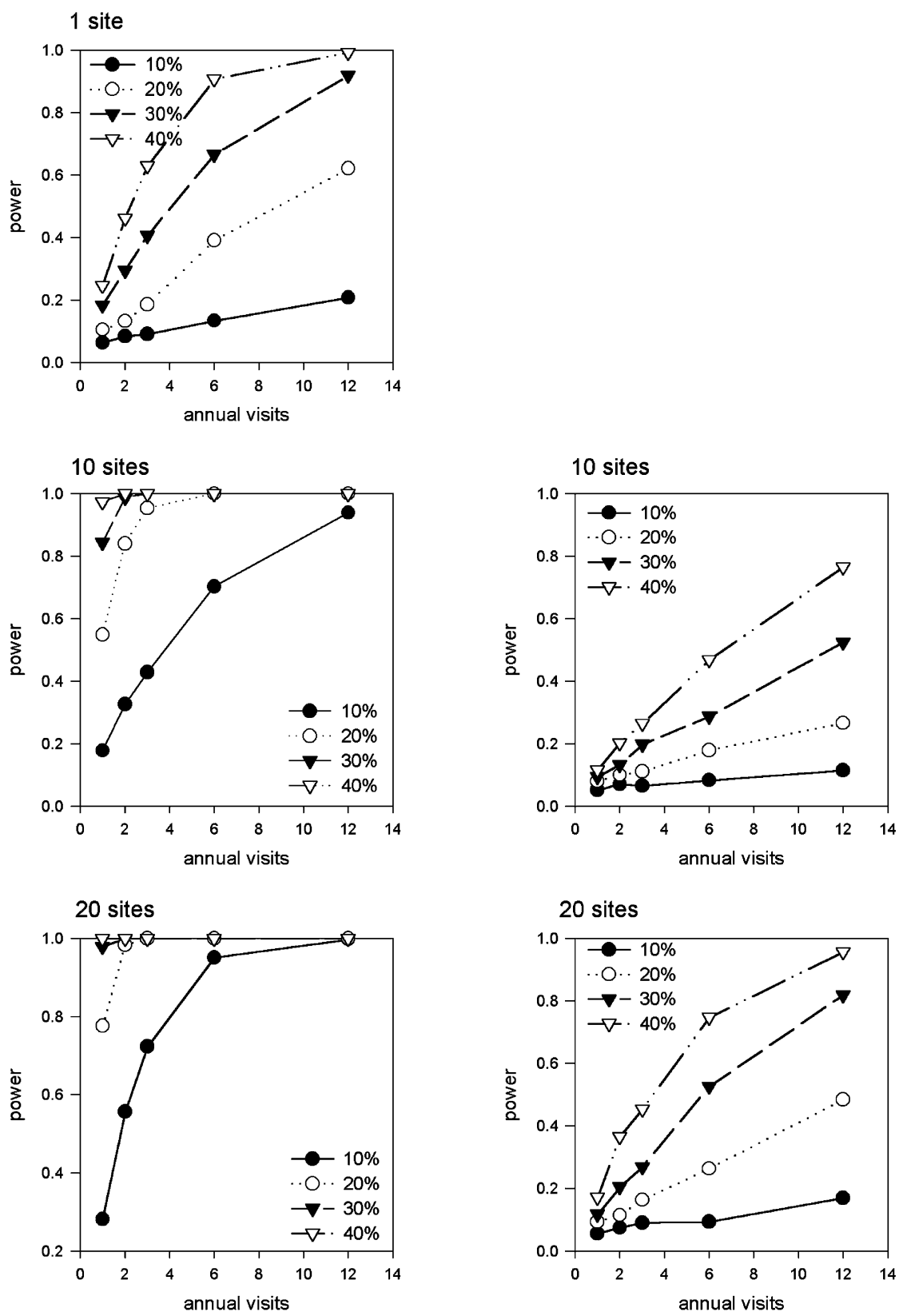

Figure 2. The power to detect population declines sampling at a single site, ten sites or 20 sites for varying number of visits per year using the 5 day mark-and-recapture estimates or the 1 day indices. 
or five sites. Figure 2 shows the power to detect declines if sampling was carried out at 10 or 20 sites. The 1 day indices would not be accurate enough to allow declines of less than $30 \%$ to be detected with meaningful power. However a $40 \%$ decline could be detected with an $80 \%$ power with 12 visits a year to 10 sites (360 person days) or a $30 \%$ decline with an $80 \%$ power with 12 visits to 20 sites (720 person days).

When the additional costs of data entry, analyses and equipment necessary for the mark-and-recapture is taken into account, the two methods may be broadly comparable in terms of power per unit cost. But both methods require a very large effort to detect relatively large declines, in practice stakeholders probably need to detect much smaller declines. This analysis shows just how difficult it is to monitor wild populations with acceptable precision to detect declines. The power to detect a decline will depend strongly on the coefficient of variation $(\mathrm{CV})$ in the estimates of abundance. Our case is not unusually bad: we found a CV of $20 \%$ and Smith (1993) states that even in western fisheries, where the value of the resource and available technical capacity is high; it is seldom affordable to carry out monitoring programmes which give a $\mathrm{CV}$ of less than $30 \%$.

\section{Conclusions from the case study}

Following the framework we proposed in the first section, Vohiparara harvesters' willingness to contribute to $\mathrm{M} \& \mathrm{M}$ will be some percentage of the annual revenue from crayfish harvesting. Although we are not able to determine this quantitatively, a number of factors suggest it will be low. For example, there are alternatives to crayfish harvesting in the area so the opportunity costs of a collapse in the crayfish harvest would not be equivalent to the full revenue. In addition, crayfish are essentially an open access resource and harvesting within the national park is technically illegal, with a threat of future enforcement preventing the harvest; these factors mean harvesters are likely to have high discount rates for this resource. Interviews suggest that crayfish have little cultural value, beyond their economic importance and the preliminary results of a study of the sustainability of crayfish harvesting suggest that harvesting is currently sustainable (Jones 2004).

Although 1 day indices could be done with little outside help, it would require a very large effort on the part of crayfish harvesters; approximately 700 days per year. Devoting this much effort to monitoring would reduce the amount of time they could spend harvesting crayfish; thus reducing the value of the resource. Their total willingness to contribute is therefore unlikely to be enough to provide a monitoring system of adequate statistical power to satisfy any of the stakeholders. They are likely therefore to opt for either the laissez faire approach, or, if conservationists considered the resource to be threatened, for a complete moratorium on harvesting (the low value of the resource making a moratorium favourable for conservationists). It is interesting to note 
that the National Park has opted for an uncompensated, yet complete moratorium which has remained un-enforced, effectively resulting in the laissez faire approach.

\section{Discussion}

We have argued that conservationists must be realistic about stakeholders' willingness to contribute to monitoring programs; this will help to prevent the collapse of programs when outsiders withdraw support. The ability of monitoring programs to contribute to the effective management of resources is largely unquantified (Danielsen et al. 2005 (this issue)), but those programs which deliver real benefits in terms of improved resource management and improved ecological integrity may often be expensive. This should come as no surprise given the difficulty experienced in the developed world in monitoring harvested populations (Beverton 1998).

Situations where the benefits of a thorough monitoring programme outweigh the costs to communities, making monitoring self-sustaining, will not be universal. If monitoring programs are to be viable they will usually require outside support - i.e. the participation of conservationists. Even with inputs from both sets of stakeholders, however, the amount available annually for a monitoring programme will usually be significantly less than twice the annual revenues from the harvest, unless moratoria carry very large social, cultural or political costs. Monitoring and management will be favoured when harvests are very valuable (culturally or financially), and populations are easy to monitor and of medium vulnerability, where communities have secure rights to the resource (lowering discount rates), and few alternatives (increasing opportunity costs of moratoria).

In our case study of freshwater crayfish harvesting in Madagascar, we found that a monitoring programme with sufficient statistical power to detect declines would be extremely costly in effort, and stakeholders willingness to contribute would be unlikely to be sufficient to make monitoring crayfish populations directly a viable option. This is likely to be a common problem, as estimating abundance of wild populations is often difficult. Where direct monitoring of an exploited species is not practical, useful information might be obtained by combining monitoring with harvesting through recording daily catches of crayfish. Such Catch Per Unit Effort (CPUE) methods would be worse than the 1 day indices at detecting declines, since there will be additional noise in the data collected.

CPUE would perform best where harvesting involves a small number of individuals and frequent returns to the same site. CPUE based methods tend to have weak power to detect declines and can be misleading as it is very difficult to be certain that effort is being recorded correctly (Robinson and Redford 1994). It may be most useful where only a small proportion of the population is currently harvested, where even weak methods can provide a warning of 
overexploitation before collapse occurs. The case of crayfish in Vohiparara seems to present some of these characteristics. We therefore suggest CPUE could have a role to play in monitoring crayfish harvesting in Vohiparara, and similar resources elsewhere. A continuum exists between pure monitoring (e.g. the 1-day indices) and monitoring a harvest (CPUE), with both cost and noise in the data varying inversely with each other along it. Different positions along the continuum could be considered, e.g. standardising some harvesting days to make them more useful for CPUE analysis but less costly than pure monitoring.

In general, greater attention must be focused on quantifying the benefits from different types of monitoring program, in terms of the increases in sustainability and sustainable yields, which they produce.

We urge those involved in setting up community M\&M programs to consider the conditions we have proposed as being likely to favour M\&M, and to use estimates of the annual net revenue of the resource as an upper limit for each stakeholder groups' contribution. This should be in addition to criteria identified in the common property literature as favouring the working of institutions (see e.g. Poteete and Ostrom 2004). We also suggest that objective appraisals of such programs (see Richards et al. 2003), which evaluate local costs and benefits of programs, could be used to test our hypotheses, enabling improved planning in the future.

\section{Acknowledgements}

This paper is an expanded version of a presentation we were invited to make at a symposium on locally-based monitoring in Denmark in April 2004 (www.monitoringmatters.org). The symposium was organized by the Nordic Agency for Development and Ecology (NORDECO, Denmark), and the Zoology Department of Cambridge University (UK). Funding from NORDECO enabled JPGJ to attend the symposium. We thank ANGAP, the University of Antananarivo and the people of Vohiparara. G. Edwards-Jones, J. Healey, N. Burgess, M. Funder, an anonymous reviewer and symposium participants made useful comments on earlier drafts. NJH was funded by the ESRC and NERC, JPGJ by NERC. Fieldwork was funded by NERC, Whitley Awards, Fauna and Flora International, The Coalbourn Trust and the Percy Sladen Memorial Fund.

\section{References}

Alvard M.S. 1998. Evolutionary ecology and resource conservation. Evol. Anthropol. 7: 62-74. Beverton R. 1998. Fish, fact and fantasy: a long view. Reviews in Fish Biology and Fisheries 8: 229-249.

Burke B.E. 2001. Hardin revisited: a critical look at perception and the logic of the commons. Hum. Ecol. 29: 449-476. 
Danielsen F., Balete D.S., Poulsen M.K., Enghoff M., Nozawa C.M. and Jensen A.E. 2000. A simple system for monitoring biodiversity in protected areas of a developing country. Biodivers. Conserv.s 9: 1671-1705.

Danielsen F., Burgess N. and Balmford A. 2005. Monitoring matters: examining the potential of locally-based approaches. Biodivers. Conserv. 14: 2507-2542.

Feeny D., Berkes F., McCay B.J. and Acheson J.M. 1990. The tragedy of the commons: twenty two years later. Hum. Ecol. 18: 1-19.

Ferraro P.J. 2002. The local costs of establishing protected areas in low-income nations: Ranomafana National Park, Madagascar. Ecol. Econ. 43: 261-275.

Jones J.P.G. 2004.The sustainability of crayfish harvesting in Ranomafana National Park, Madagascar. PhD, University of Cambridge, Cambridge, UK (available electronically from JPGJ).

Korhonen K., Rahkonen O. and Hemminki E. 2004. Implications of integrated conservation for human reproductive health: a case study from Ranomafana National Park. Development Southern Africa. 21: 603-621.

Kremen C., Raymond I. and Lances K. 1998. An interdisciplinary tool for monitoring conservation impacts in Madagascar. Conserv. Biol. 12: 549-563.

Leach M., Mearns R. and Scoones I. 1999. Environmental entitlements: dynamics and institutions in community-based natural resource management. World Development 27: 225-247.

Mace G.M. and Reynolds J.D. 2001. Exploitation as a conservation issue. In: Reynolds J.D., Mace G.M., Redford K.H. and Robinson J.G. (eds), Conservation of Exploited Species. Cambridge University Press, Cambridge, UK, pp. 3-15.

Pimentel D., McNair M., Duck L., Pimentel M. and Kamil J. 1997. The value of forests to world food security. Hum. Ecol. 25: 91-120.

Policansky D. 1993. Uncertainty, knowledge, and resource management. Ecol. Appl. 3: 583-584.

Poteete A.R. and Ostrom E. 2004. Heterogeneity, group size and collective action: the role of institutions in forest management. Dev. Change 35: 435-461.

Richards M., Davies J. and Yaron G. 2003. Stakeholder Incentives in Participatory Forest Management. ODI, London, UK.

Robinson J.G. and Redford K.H. 1994. Measuring the sustainability of hunting in tropical forests. Oryx 28: 249-256.

Sheil D. 2001. Conservation and biodiversity monitoring in the tropics: realities, priorities, and distractions. Conserv. Biol. 15: 1179-1182.

Smith P.E. 1993. Balancing sampling precision and fisheries management: objectives, minimal methods. Bull. Mar. Sci. 53: 930-935.

Topp-Jørgensen E., Poulsen M.K., Lund J.F. and Massao J.F. 2005. Community-based monitoring of natural resource use and forest quality in montane forests and miombo woodlands in Iringa District, Tanzania. Biodivers. Conserv. 14: 2653-2677.

White G.C. and Burnham K.P. 1999. Program MARK: survival estimations from populations of marked birds. Bird Study 46: 120-138.

Wong J.G., Thornber K. and Baker N. 2001. Resource Assessment of Non-wood Forest Products. Food and Agriculture Organization, Rome, Italy.

Wright P.C. and Andriamihaja B. 2004. The conservation value of long-term research: a case study from Parc National de Ranomafana. In: Goodman S.M. and Benstead J.P (eds), The Natural History of Madagascar. University of Chicago Press, Chicago, USA, pp. 1485-1488. 